Supporting Information for the article entitled

\title{
Heterogeneous Orientational Relaxations and Translation-Rotation Decoupling in (Choline Chloride + Urea) Deep Eutectic Solvents: Investigation Through Molecular Dynamics Simulations and Dielectric Relaxation Measurements
}

Juriti Rajbangshi, Kallol Mukherjee, and Ranjit Biswas*

${ }^{1}$ Department of Chemical, Biological and Macro-molecular Sciences, S N Bose National Centre for Basic Sciences, JD-Block, Sector-III, Kolkata-700106, India

* Address for correspondence:

*: ranjit@bose.res.in; phone: +91 332335 5706; FAX:+91 3323353477 
Table S1. Partial charges and Lennard-Jones parameters for choline and chloride ions. Atomic sites of choline ion are denoted as follows:

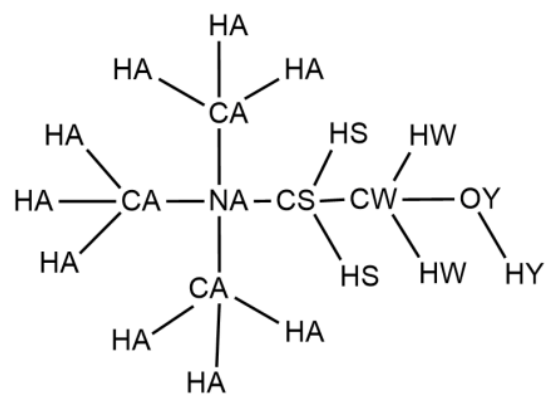

\begin{tabular}{|c|c|c|c|}
\hline Atoms & Charge (e) & $\varepsilon(\mathrm{kcal} / \mathrm{mol})$ & $\sigma(\AA)$ \\
\hline CS & -0.131 & 0.066 & 3.50 \\
\hline HS & 0.068 & 0.030 & 2.60 \\
\hline NA & 0.791 & 0.170 & 3.25 \\
\hline CA & -0.100 & 0.066 & 3.50 \\
\hline CW & 0.132 & 0.066 & 3.50 \\
\hline OY & -0.468 & 0.170 & 3.07 \\
\hline HA & 0.033 & 0.030 & 2.50 \\
\hline HW & 0.034 & 0.030 & 0.00 \\
\hline HY & 0.275 & 0.000 & 3.77 \\
\hline Cl & -0.800 & 0.148 & \\
\hline
\end{tabular}


Table S2. Partial charges and Lennard-Jones parameters for urea molecules. Atom sites of urea molecule are denoted as follows:<smiles>CN([In])C(=O)N(C)[IH]</smiles>

\begin{tabular}{|c|c|c|c|}
\hline Atoms & Charge (e) & $\varepsilon(\mathrm{kcal} / \mathrm{mol})$ & $\sigma(\AA)$ \\
\hline $\mathrm{C}$ & 0.124 & 0.1575 & 3.75 \\
\hline $\mathrm{O}$ & -0.322 & 0.3150 & 2.96 \\
\hline $\mathrm{N}$ & -0.453 & 0.2550 & 3.55 \\
\hline $\mathrm{HT}$ & 0.276 & 0.0000 & 0.00 \\
\hline $\mathrm{HC}$ & 0.276 & 0.0000 & 0.00 \\
\hline
\end{tabular}




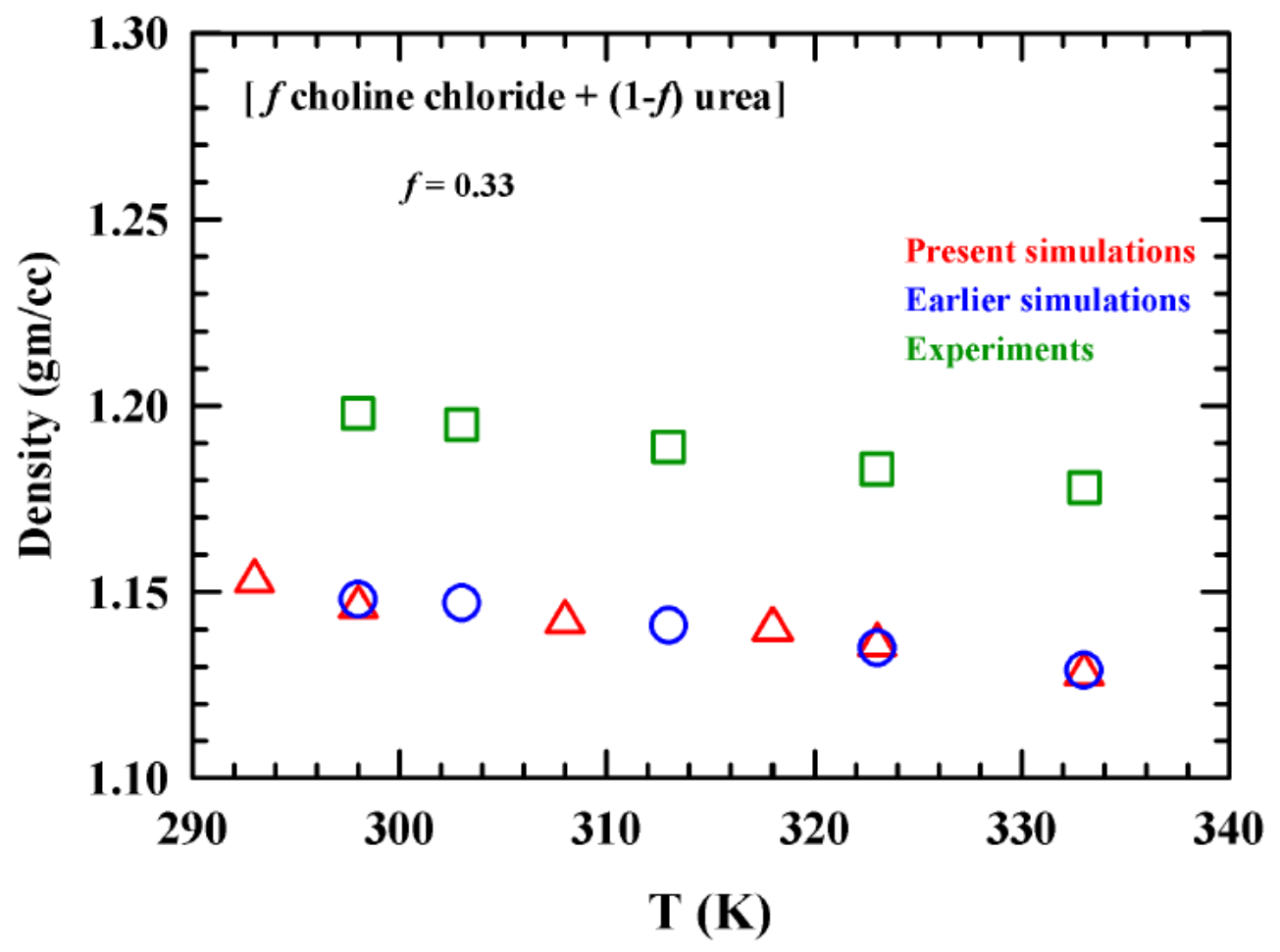

Figure S1. Comparison of temperature dependent densities of [ $f$ choline chloride $+(1-f)$ urea] DESs for $f=0.33$ obtained from the present simulations with those from earlier simulation studies and experiments. 


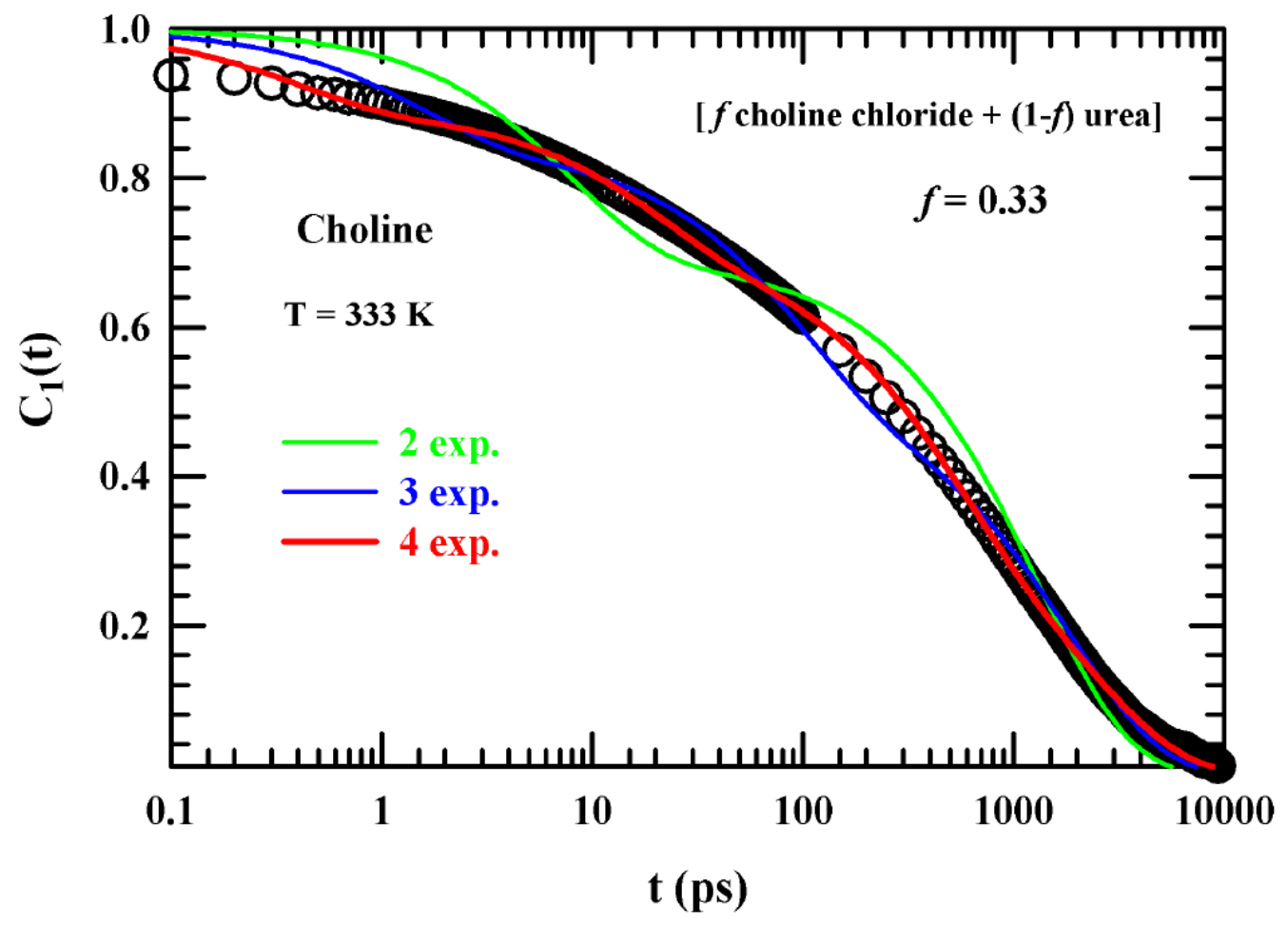

Figure S2. The figure shows a comparison among various exponential functions ( 2 exp., 3 exp. and 4 exp.) as fit functions for adequately describing the simulated $C_{1}(t)$ relaxation for choline ion in $[f$ choline chloride $+(1-f)$ urea $]$ DESs at $333 \mathrm{~K}$. This representative figure suggests that the $C_{1}(t)$ relaxation requires a four exponential fit. Similar observation has been made for other temperatures also. 


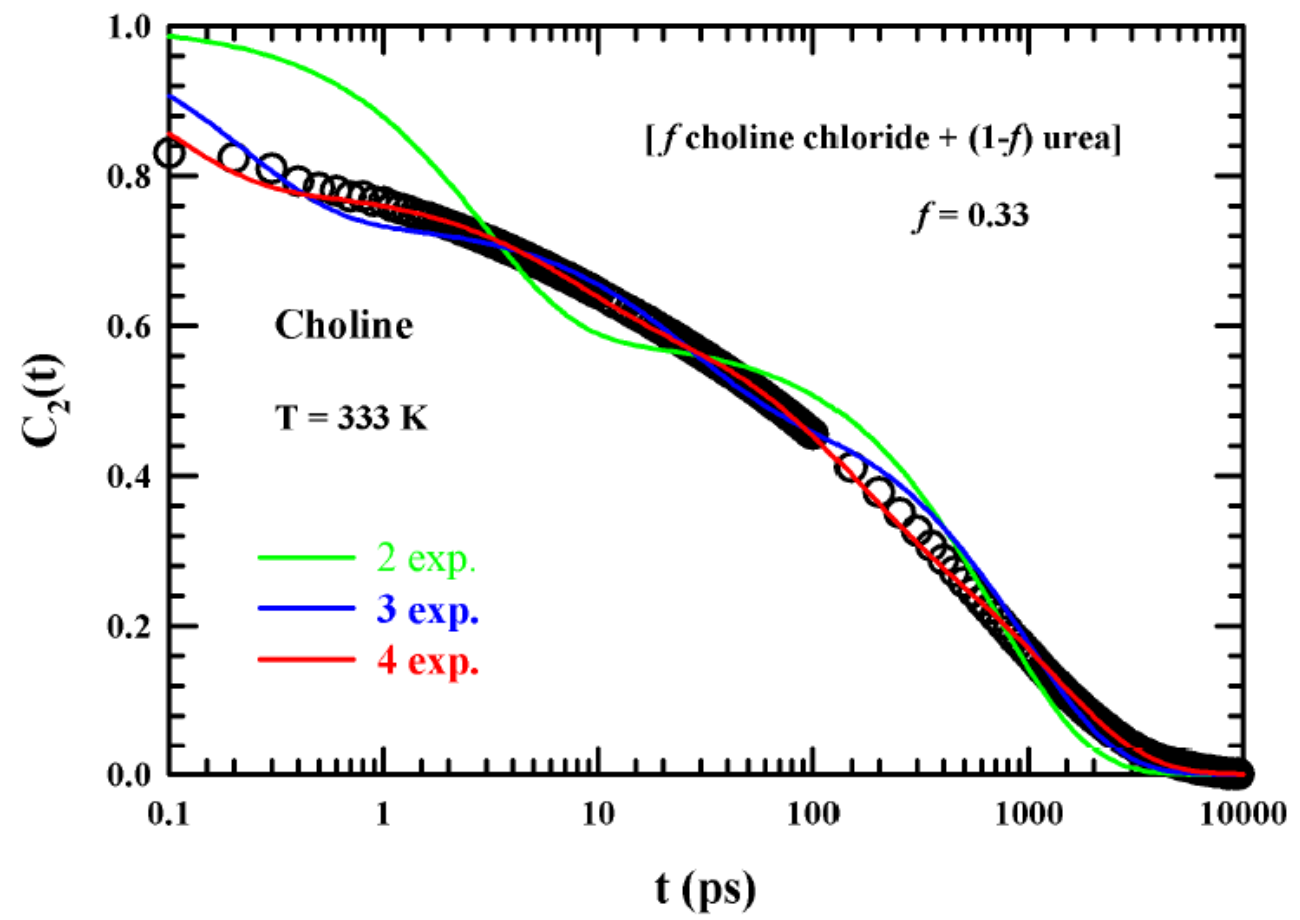

Figure S3. The figure shows a comparison among various exponential functions ( 2 exp., 3 exp. and 4 exp.) to fit the simulated $C_{2}(t)$ relaxation for choline ion in [ $f$ choline chloride $+(1-f)$ urea] DESs at $333 \mathrm{~K}$. 


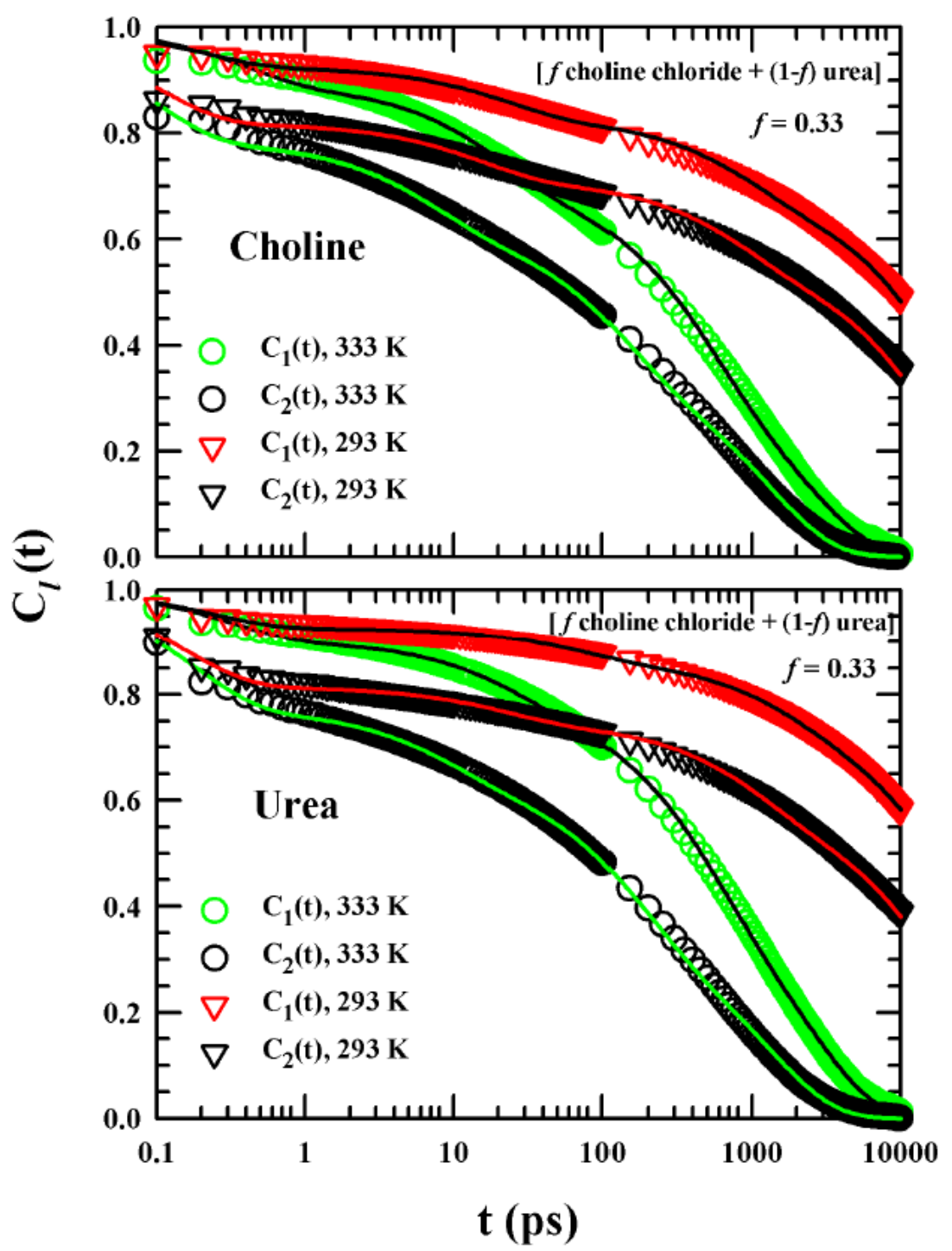

Figure S4. Simulated rank dependent collective single particle reorientational correlation functions $\left(C_{l}(t)\right)$ of rank $l=1$ and 2 for choline (upper panel) and urea (lower panel) in [ $f$ choline chloride $+(1-f)$ urea] DES for $f=0.33$ at two representative temperatures, $\mathrm{T}=293,333$ $\mathrm{K}$. The lines going through the simulated data are the multi-exponential fits. 
Table S3: Temperature dependent experimental viscosity coefficients of $[f$ choline chloride + $(1-f)$ urea) DES for $f=0.33^{\text {a }}$.

\begin{tabular}{|c|c|c|}
\hline $\mathrm{T}(\mathrm{K})$ & $\eta(\mathrm{cP})^{1}$ & $\eta(\mathrm{cP})^{2}$ \\
\hline 293 & 1371.653 & 1412 \\
\hline 298 & 859.454 & 631 \\
\hline 303 & 527.090 & 411 \\
\hline 308 & 348.248 & 278 \\
\hline 313 & 237.931 & 195 \\
\hline 318 & 175.067 & 141 \\
\hline 323 & 119.721 & 80 \\
\hline 333 & - & \\
\hline
\end{tabular}

Refs. ${ }^{1}$ H. Shekaari, M.T. Zafarani-Moattar, B. Mohammadi, J. Mol. Liq. 243 (2017) 451-461.

2 A. Das, R. Biswas J. Phys. Chem. B 119, (2015) 10102-10113.

${ }^{\text {a }}$ Viscosity values in column 3 are better than $\pm 5 \%$ of the tabulated values. 
Table S4. Ratios of average simulated reorientational correlation times obtained from $C_{l}(t)$ of rank, $l=1$ and 2 for choline and urea in [ $f$ choline chloride $+(1-f)$ urea] DESs for $f=0.33$ at various temperatures.

\begin{tabular}{|c|c|c|c|}
\hline $\mathrm{T}(\mathrm{K})$ & $\begin{array}{c}\langle\tau\rangle_{l=1} \\
(\mathrm{ps})\end{array}$ & $\begin{array}{c}\langle\tau\rangle_{l=2} \\
(\mathrm{ps})\end{array}$ & $\frac{\langle\tau\rangle_{l=1}}{\langle\tau\rangle_{l=2}}$ \\
\hline \multicolumn{4}{|c|}{ Choline } \\
\hline 293 & 20038 & 11754 & 1.7 \\
\hline 298 & 17971 & 10364 & 1.7 \\
\hline 308 & 10405 & 6223 & 1.7 \\
\hline 318 & 5090 & 1963 & 2.6 \\
\hline 323 & 2513 & 1772 & 1.4 \\
\hline 333 & 1057 & 484 & 2.2 \\
\hline \multicolumn{4}{|c|}{ Urea } \\
\hline 293 & 29823 & 14082 & 2.1 \\
\hline 298 & 25606 & 11794 & 2.2 \\
\hline 308 & 13259 & 6229 & 2.1 \\
\hline 318 & 5863 & 2042 & 2.8 \\
\hline 323 & 2925 & 1319 & 2.2 \\
\hline 333 & 1294 & 489 & 2.6 \\
\hline
\end{tabular}




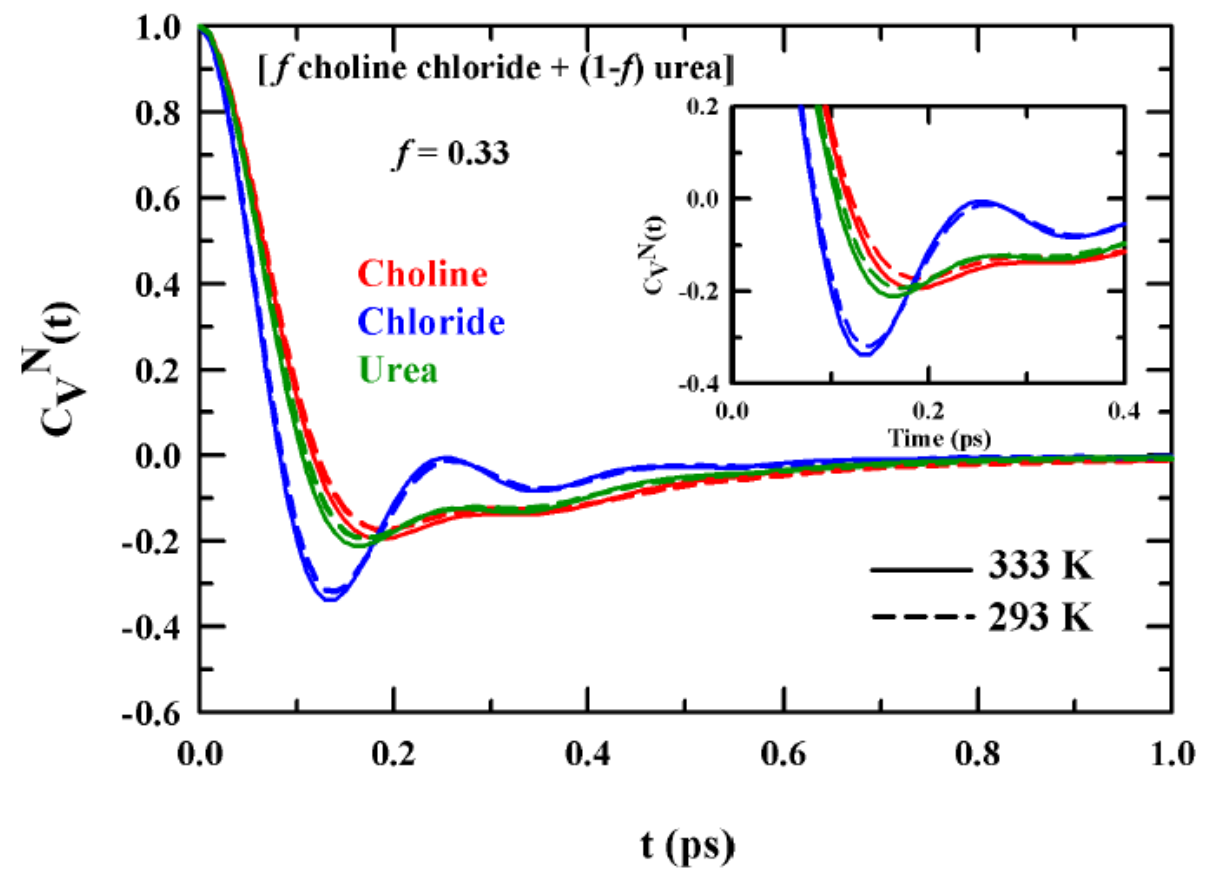

Figure S5. Normalized velocity autocorrelation functions (VACFs), $C_{v}^{N}(t)$, of choline cation, chloride anion and urea in [ $f$ choline chloride $+(1-f)$ urea] DES for $f=0.33$ at temperatures 293 and $333 \mathrm{~K}$. The inset shows the VACF at short times to highlight the marked cage-rattling of chloride ion in this DES. 

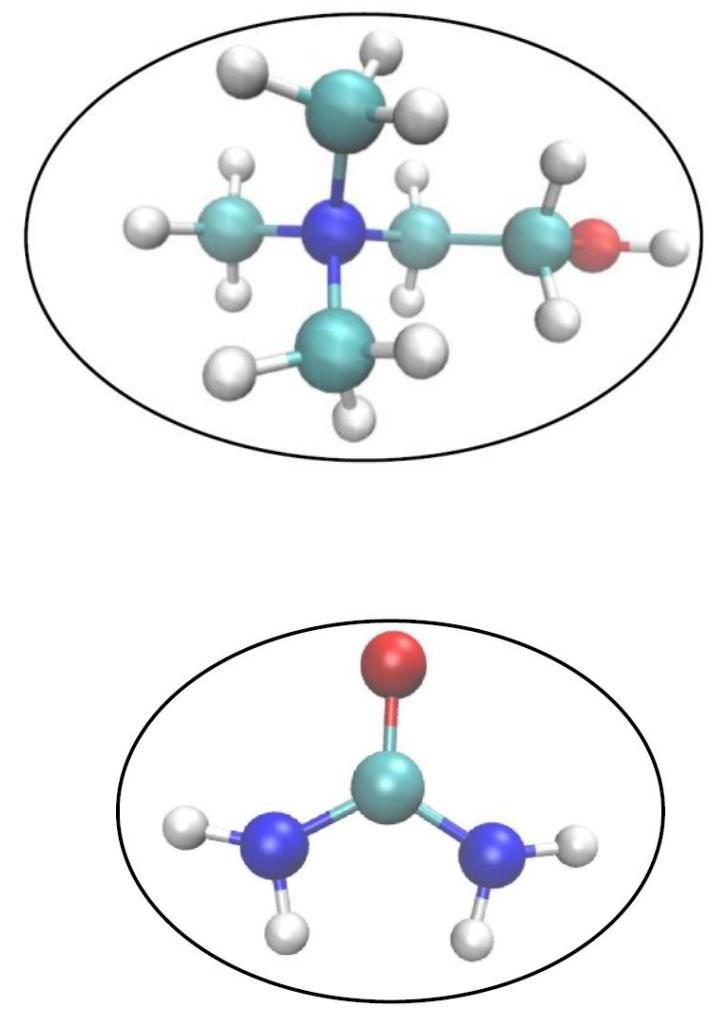

Figure S6. Shape of choline cation and urea molecule as an approximate oblate spheroid. 


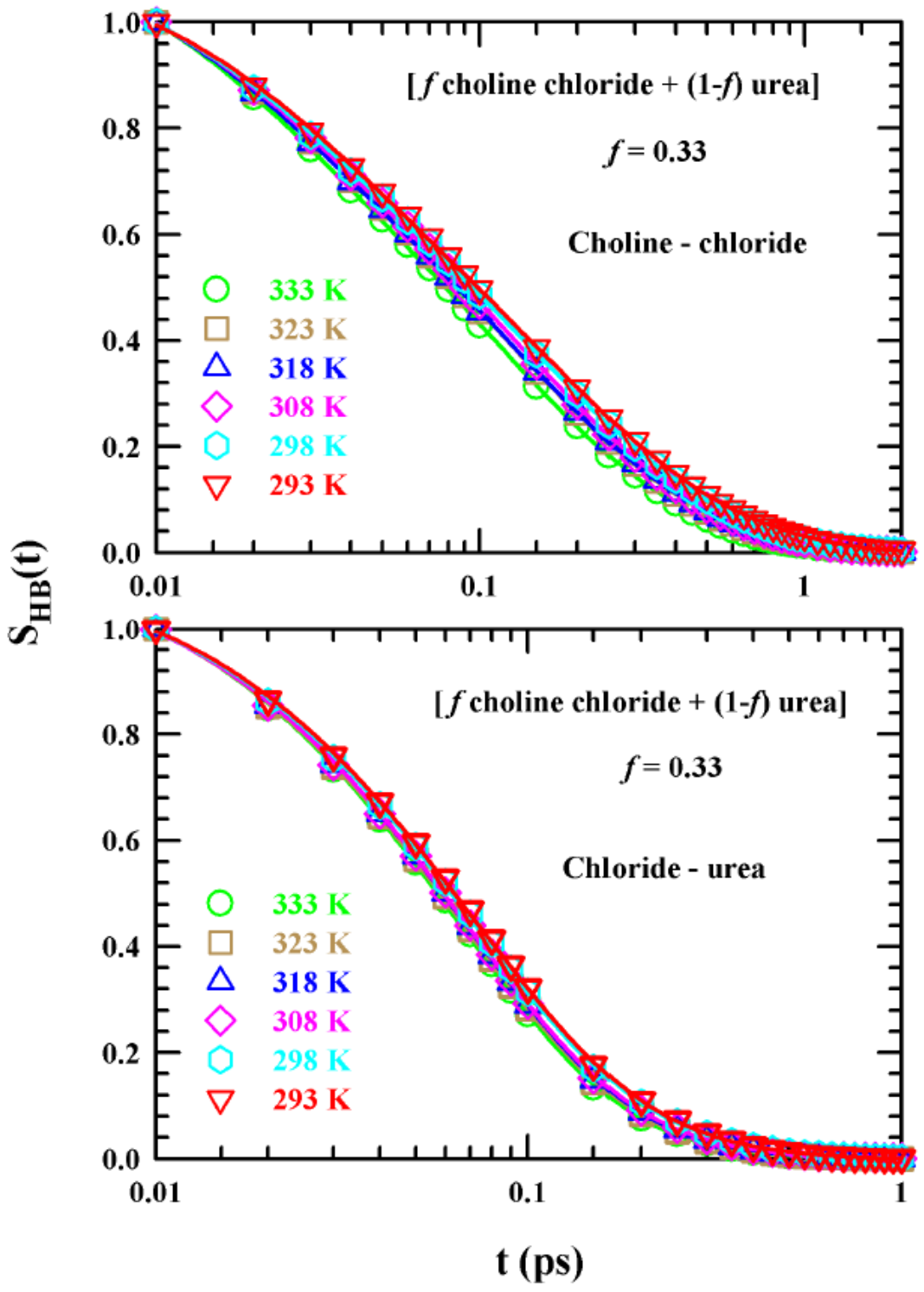

Figure S7. Temperature dependence of the simulated decays of the continuous H-bond relaxation functions, $S_{H B}(t)$, for choline - chloride (upper panel) and chloride - urea (lower panel) H-bonds in $[f$ choline chloride $+(1-f)$ urea $]$ DES at $f=0.33$. 
Table S5. Multi-exponential fit parameters for the simulated H-bond relaxations, $S_{H B}(t)$ for choline - chloride and chloride - urea pairs in [ $f$ choline chloride $+(1-f)$ urea DESs for $f=0.33$ at various temperatures.

\begin{tabular}{|c|c|c|c|c|c|c|c|}
\hline $\mathrm{T}(\mathrm{K})$ & $\mathrm{a}_{1}$ & $\begin{array}{c}\tau_{1} \\
(\mathrm{ps})\end{array}$ & $a_{2}$ & $\begin{array}{c}\tau_{2} \\
(\mathrm{ps})\end{array}$ & $a_{3}$ & $\begin{array}{c}\tau_{3} \\
(\mathrm{ps})\end{array}$ & $\begin{array}{c}\langle\tau\rangle \\
(\mathrm{ps})\end{array}$ \\
\hline \multicolumn{8}{|c|}{ Choline - chloride } \\
\hline 293 & 0.3304 & 0.0268 & 0.5313 & 0.14 & 0.28 & 0.45 & 0.21 \\
\hline 298 & 0.3327 & 0.0244 & 0.5264 & 0.13 & 0.29 & 0.40 & 0.20 \\
\hline 308 & 0.3173 & 0.0221 & 0.5277 & 0.12 & 0.32 & 0.35 & 0.18 \\
\hline 318 & 0.3322 & 0.0213 & 0.5333 & 0.11 & 0.31 & 0.34 & 0.17 \\
\hline 323 & 0.3282 & 0.0222 & 0.5432 & 0.12 & 0.30 & 0.34 & 0.17 \\
\hline 333 & 0.3323 & 0.0191 & 0.5429 & 0.10 & 0.32 & 0.29 & 0.15 \\
\hline \multicolumn{8}{|c|}{ Chloride - urea } \\
\hline 293 & 0.5096 & 0.0676 & 0.4616 & 0.0676 & 0.1660 & 0.1947 & 0.098 \\
\hline 298 & 0.5247 & 0.0673 & 0.4751 & 0.0672 & 0.1394 & 0.2118 & 0.097 \\
\hline 308 & 0.5339 & 0.0645 & 0.4870 & 0.0645 & 0.1261 & 0.1927 & 0.090 \\
\hline 318 & 0.5398 & 0.0651 & 0.4957 & 0.0651 & 0.1129 & 0.1876 & 0.088 \\
\hline 323 & 0.5400 & 0.0639 & 0.4968 & 0.0639 & 0.1139 & 0.1799 & 0.087 \\
\hline 333 & 0.5546 & 0.0637 & 0.5123 & 0.0637 & 0.0881 & 0.1851 & 0.084 \\
\hline
\end{tabular}




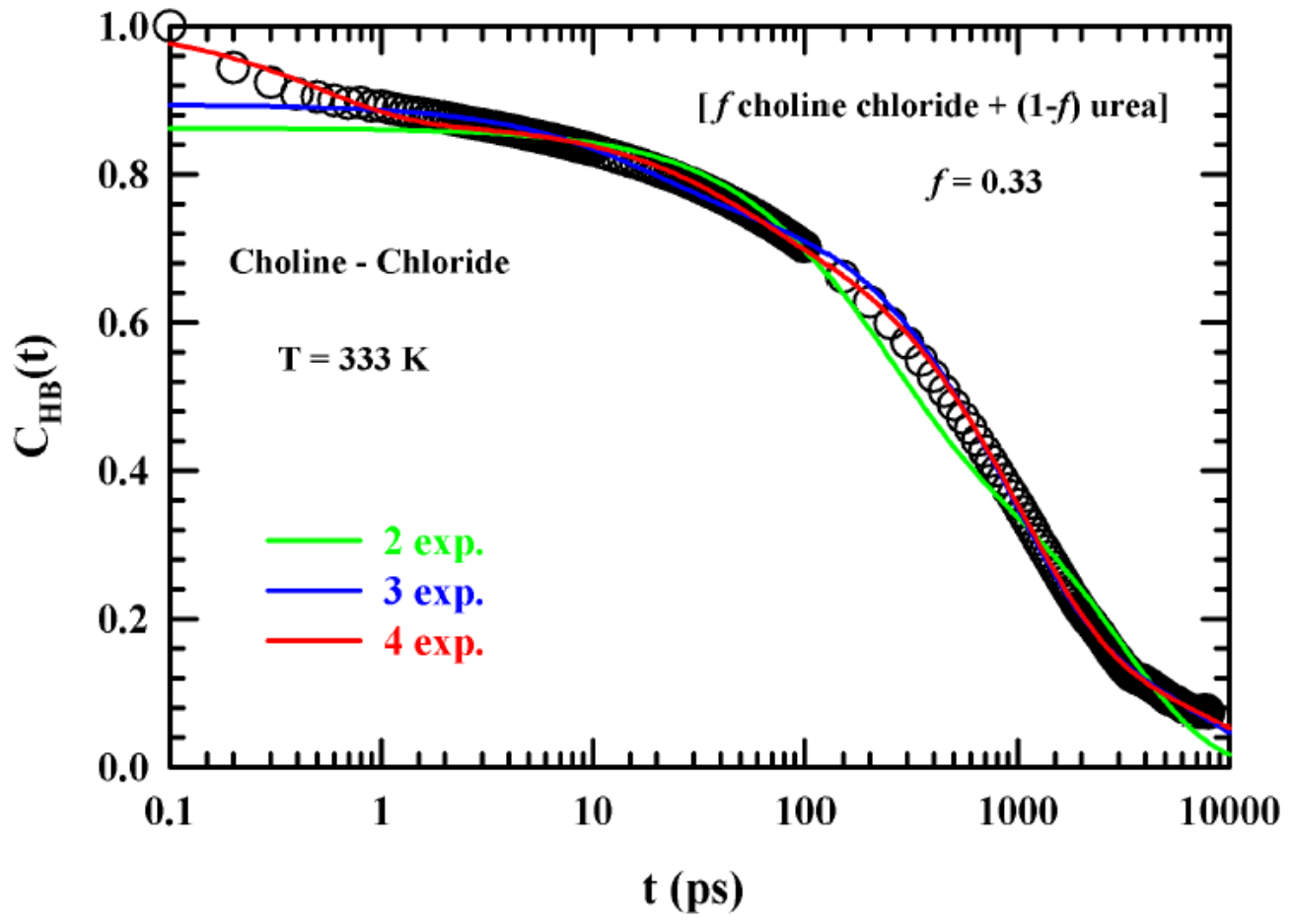

Figure S8. The figure shows a comparison among various exponential fit functions (2 exp., 3 exp. and 4 exp.) for describing the $C_{H B}(t)$ relaxation for choline - chloride pair in in $[f$ choline chloride $+(1-f)$ urea] DESs at $333 \mathrm{~K}$. 
Table S6. Molecular diameter of choline, chloride and urea used in the calculations.

\begin{tabular}{|c|c|}
\hline Molecule/ion & $\begin{array}{c}\text { Diameter } \\
(\AA)\end{array}$ \\
\hline Choline & 3.29 \\
\hline Chloride & 3.62 \\
\hline Urea & 4.7 \\
\hline
\end{tabular}

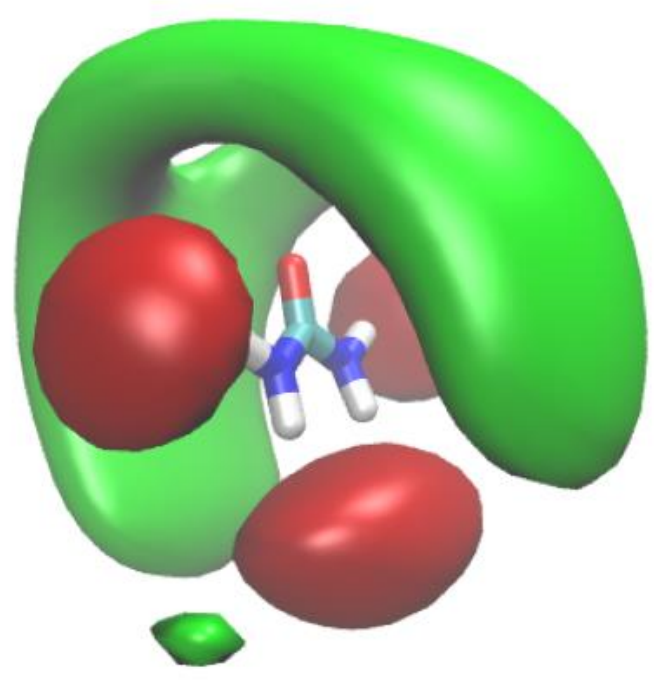

Figure S9. Spatial distribution functions (SDFs) for choline (green frame) and chloride ion (red frame) around a urea molecule. 
Table S7. Values for $\tau_{N G}$ and $\tau_{N N G}$ from simulations of [ $f$ choline chloride $+(1-f)$ urea] DES for $f=0.33$ at 293 and $333 \mathrm{~K}$.

\begin{tabular}{|c|c|c|c|}
\hline Molecule/ion & $\mathrm{T}(\mathrm{K})$ & $\tau_{N G}(\mathrm{~ns})$ & $\tau_{N N G}(\mathrm{~ns})$ \\
\hline \multirow{2}{*}{ Choline } & 293 & $>15$ & $>15$ \\
\cline { 2 - 4 } & 333 & 0.52 & 0.81 \\
\hline Urea & 293 & 2.94 & $>15$ \\
\cline { 2 - 4 } & 333 & 0.28 & 1.04 \\
\hline
\end{tabular}




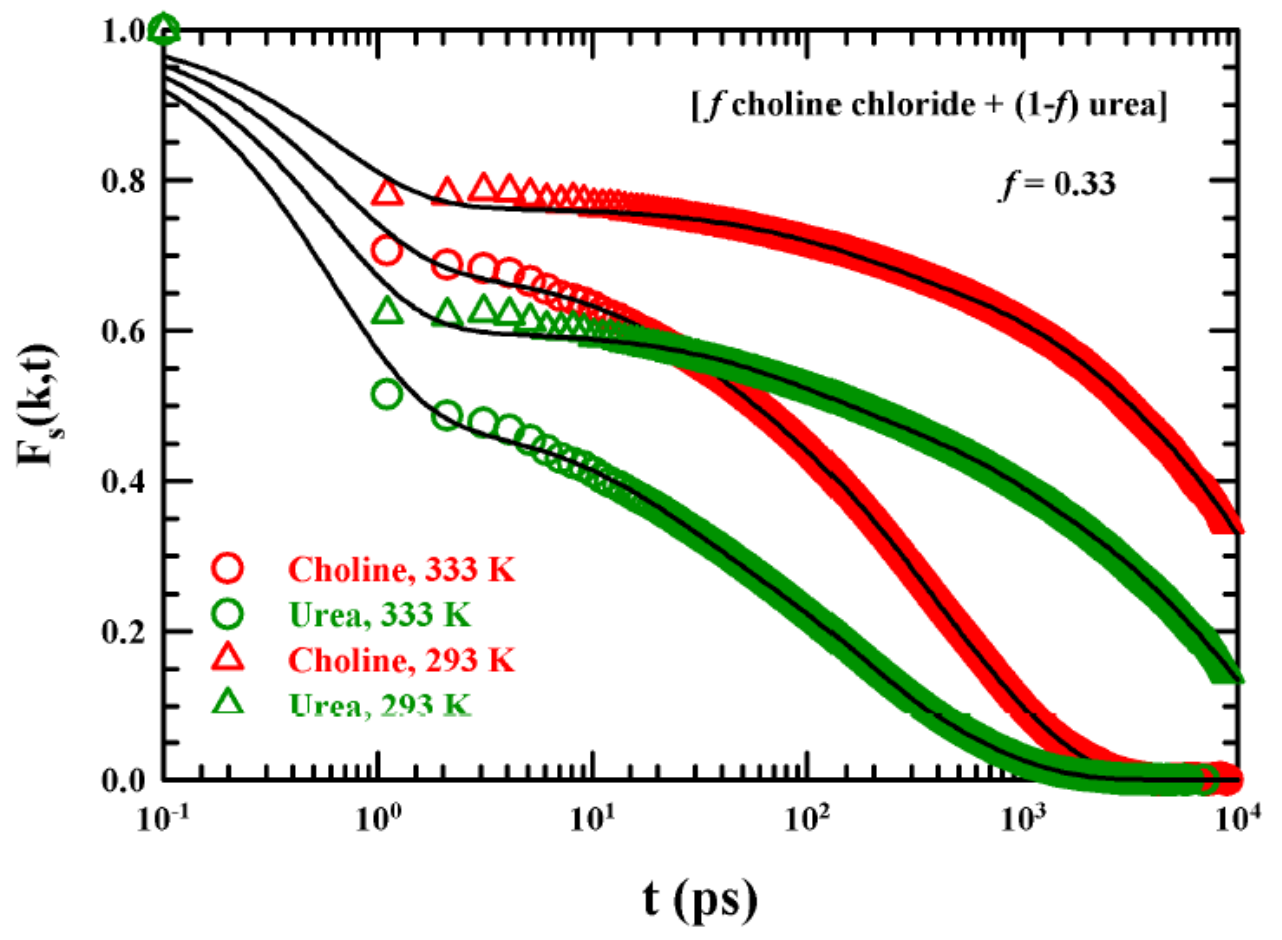

Figure S10. Simulated self-dynamic structure factor, $F_{s}(k, t)$ for choline (circle) and urea (triangle) at the nearest neighbor wavenumber $(k \sigma \rightarrow 2 \pi)$ in $[f$ choline chloride $+(1-f)$ urea] DES for $f=0.33$ at temperatures 293 and $333 \mathrm{~K}$. Symbols represent the simulated data and the lines going through the data are the best fits (stretched/multi-exponential). 
Table S8: Stretched/multi-exponential fit parameters for the simulated self-part of dynamic structure factor, $F_{S}(k, t)$ for choline ion and urea molecule in [ $f$ choline chloride $+(1-f)$ urea] DESs at 293 and $333 \mathrm{~K}$ for $f=0.33$.

\begin{tabular}{|c|c|c|c|c|c|c|c|c|c|c|c|}
\hline $\mathrm{T}(\mathrm{K})$ & $\begin{array}{c}\text { Ion and } \\
\text { molecule }\end{array}$ & $a_{1}$ & $\begin{array}{c}\tau_{1} \\
(\mathrm{ps})\end{array}$ & $a_{2}$ & $\begin{array}{c}\tau_{2} \\
(\mathrm{ps})\end{array}$ & $a_{3}$ & $\begin{array}{c}\tau_{3} \\
(\mathrm{ps})\end{array}$ & $a_{4}$ & $\begin{array}{c}\tau_{4} \\
(\mathrm{ps})\end{array}$ & $\begin{array}{c}\langle\tau\rangle \\
(\mathrm{ps})\end{array}$ \\
\hline 333 & Choline & 0.32 & 0.6 & 0.20 & 184 & 0.12 & 27 & 0.36 & 279 & 0.36 & 142 \\
\hline & Urea & 0.52 & 0.6 & 0.13 & 20 & 0.20 & 140 & 0.15 & 572 & 1 & 116 \\
\hline 293 & Choline & 0.24 & 0.6 & 0.07 & 150 & 0.11 & 1658 & 0.58 & 3129 & 0.18 & 2012 \\
\hline & Urea & 0.40 & 0.6 & 0.09 & 89 & 0.40 & 9170 & 0.11 & 778 & 1 & 3776 \\
\hline
\end{tabular}




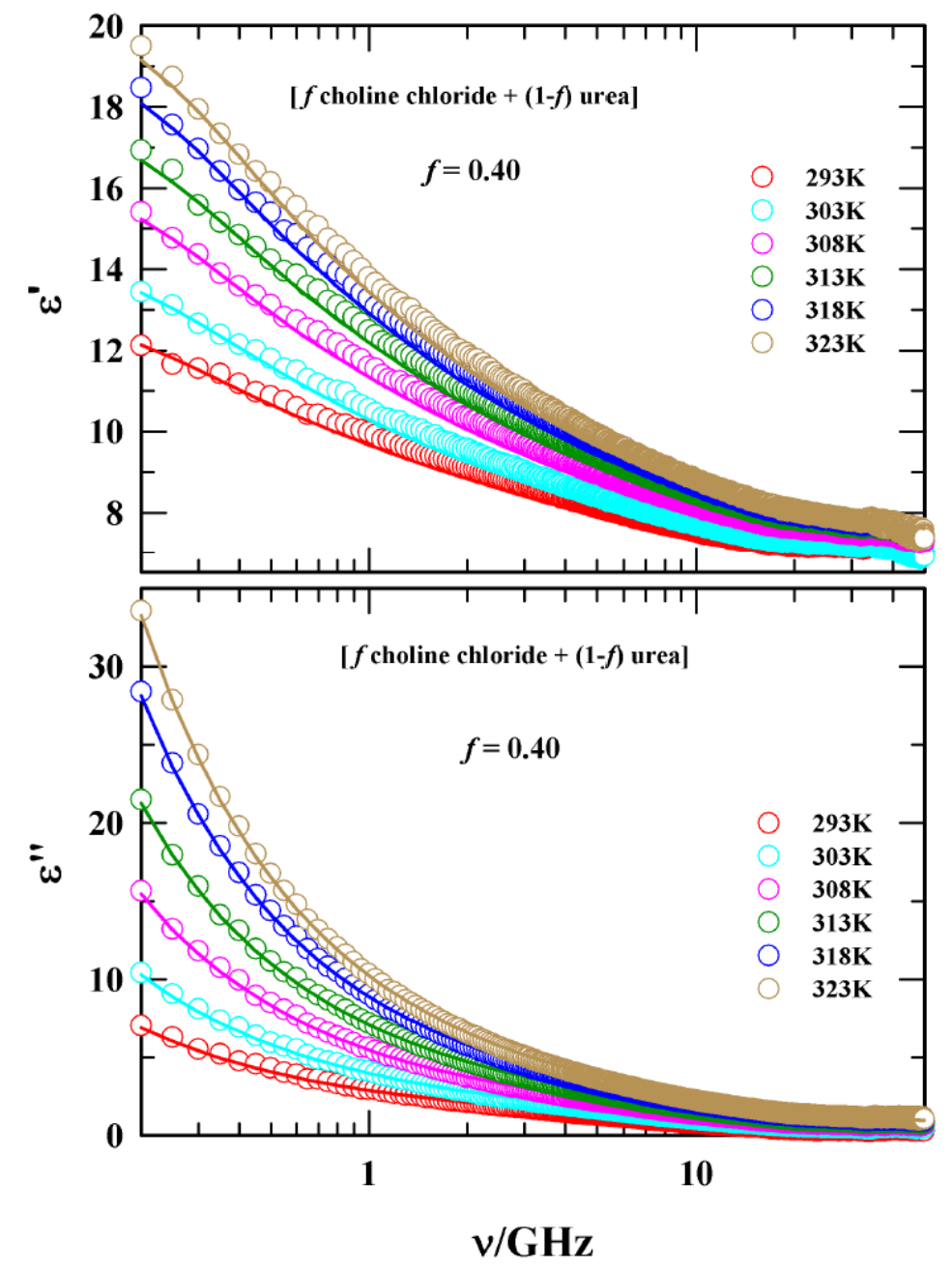

Figure S11. Temperature dependence of the real $\left(\varepsilon^{\prime}\right)$ and imaginary $\left(\varepsilon^{\prime \prime}\right)$ components of the measured DR spectra for $[f$ choline chloride $+(1-f)$ urea DES at $f=0.40$ within the frequency regime $0.2 \leq v / \mathrm{GHz} \leq 50$. Solid lines through these data represent simultaneous fits using 4Debye relaxation model. Representations are color-coded. 


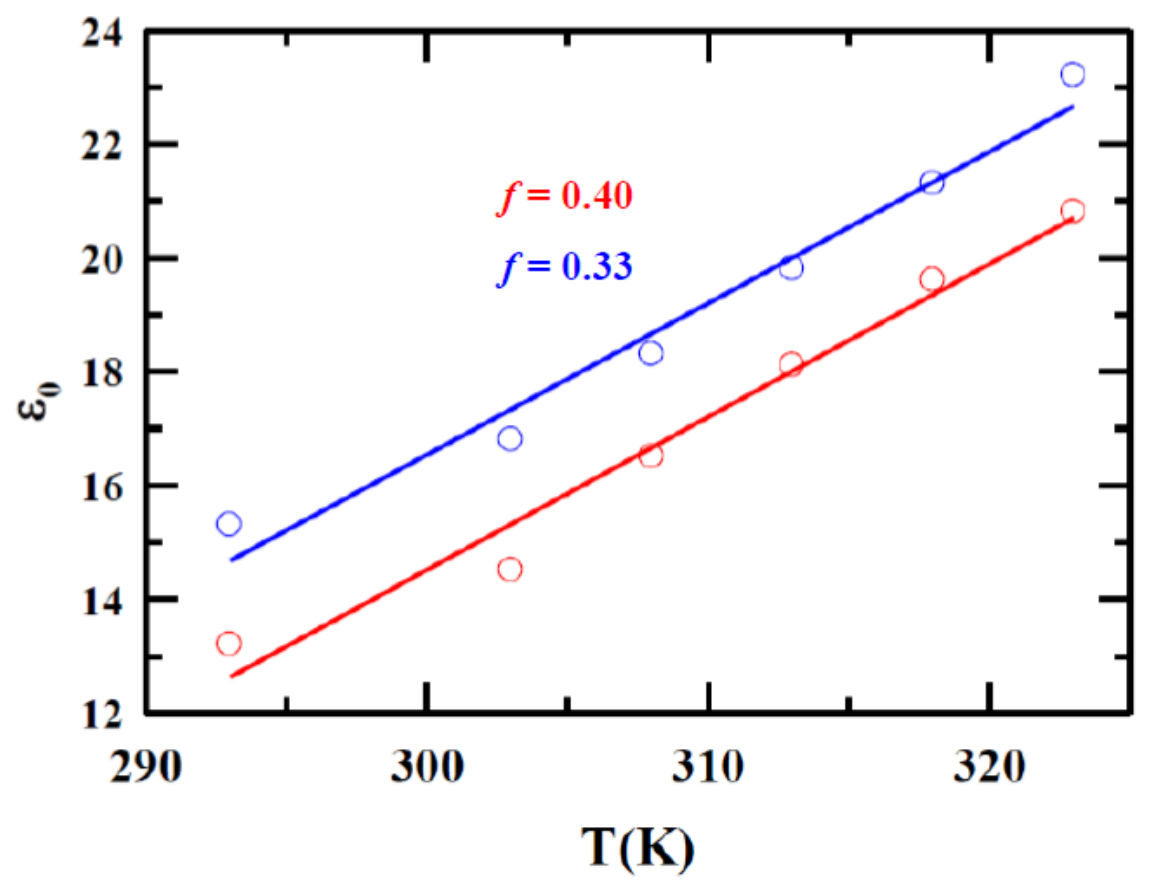

Figure S12. Temperature dependence of the estimated static dielectric constant $\left(\varepsilon_{0}\right)$ for $f=$ 0.40 and $f=0.33$. Data for different compositions are color coded. 


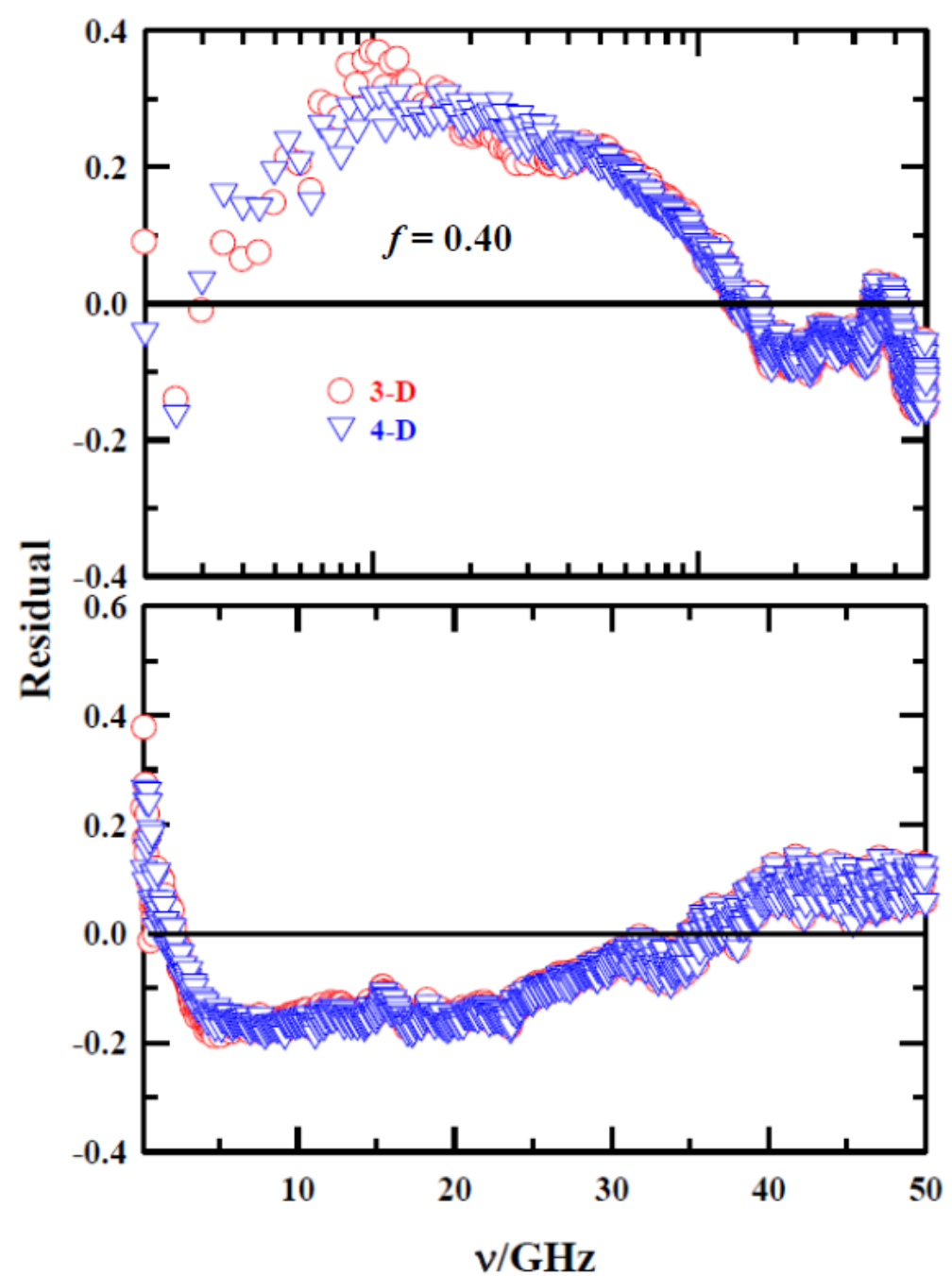

Figure S13. Comparison between 4-Debye and 3-Debye fits to the $\varepsilon^{\prime}$ (upper panel) and $\varepsilon^{\prime \prime}$ (lower panel) of the complex DR spectra of [ $f$ choline chloride $+(1-f)$ urea] DES for $f=0.40$ at $293 \mathrm{~K}$. 


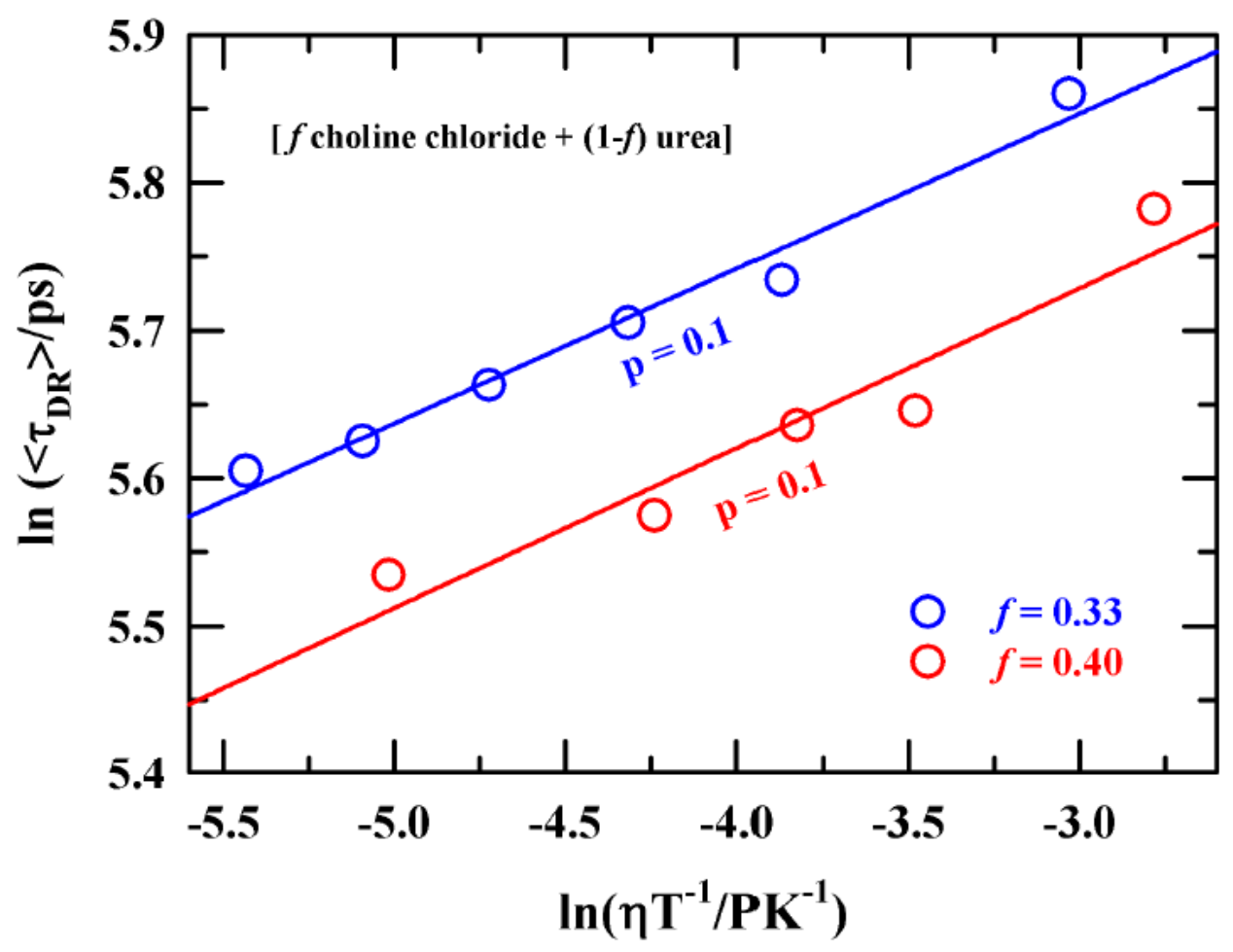

Figure S14. Viscosity decoupling of average DR times, $\left\langle\tau_{D R}\right\rangle$ in $[f$ choline chloride $+(1-f)$ urea] DES at $f=0.40$ (circles) and 0.33 (triangles). Here, the slowest DR times are shown as a function of the temperature-reduced viscosity $(\eta / T)$. Fits through the data are represented by the solid lines. 